\title{
Conservative management versus surgical drainage in pancreatic pseudocyst
}

\author{
Abdullah Almaihan ${ }^{1 *}$, Ahmed Matar ${ }^{2}$, Eman Murshid ${ }^{3}$, Sama Al-Ostaz ${ }^{4}$, Ahmed Shebly ${ }^{5}$, \\ Mohammed Miftah $^{6}$, Eman Alsaif ${ }^{7}$, Doaa Alzaher ${ }^{8}$, Hadi Alyami', Fetoun Al-Ajmi ${ }^{10}$
}

\author{
${ }^{1}$ Department of Surgery, Prince Saud bin Jalawy Hospital, Al-Hofuf, Saudi Arabia \\ ${ }^{2}$ Department of Surgery, King Khaled Hospital and Prince Sultan Center For Health Care, Al-Kharj, Saudi Arabia \\ ${ }^{3}$ College of Medicine, Ibn Sina National College, Jeddah, Saudi Arabia \\ ${ }^{4}$ College of Medicine, Batterjee Medical College, Jeddah, Saudi Arabia \\ ${ }^{5}$ College of Medicine, Umm Al-Qura University, Mecca, Saudi Arabia \\ ${ }^{6}$ College of Medicine, Jazan University, Jazan, Saudi Arabia \\ ${ }^{7}$ College of Medicine, Imam Abdulrahman Bin Faisal university, Dammam, Saudi Arabia \\ ${ }^{8}$ College of Medicine, Medical University of Warsaw, Warsaw, Poland \\ ${ }^{9}$ College of Medicine, Najran University, Najran, Saudi Arabia \\ ${ }^{10}$ College of Medicine, King Faisal University, Al-Ahsa, Saudi Arabia
}

Received: 24 May 2018

Accepted: 28 May 2018

\section{*Correspondence:}

Dr. Abdullah Almaihan,

E-mail: hbh20010@gmail.com

Copyright: (c) the author(s), publisher and licensee Medip Academy. This is an open-access article distributed under the terms of the Creative Commons Attribution Non-Commercial License, which permits unrestricted non-commercial use, distribution, and reproduction in any medium, provided the original work is properly cited.

\begin{abstract}
Pancreatic pseudocyst is not an uncommon complication of acute or chronic pancreatitis. It often presents with persistent abdominal pain and tenderness after the resolution of pancreatitis. Two lines of management are available for treatment of pancreatic pseudocyst: conservative management and surgical drainage. Conservative management is preferred in small-sized, asymptomatic, and short-lasting pseudocysts, whilst surgical management is often indicated when the cysts are larger in size, symptomatic, long-lasting, or when complications occur. Overall, 50\% of cysts resolve spontaneously and only require conservative management, whilst surgical management is indicated for prevention of potential complications. This article will review and discuss in detail and compare between conservative management and surgical drainage of pseudocyst as regards indications, advantages, disadvantages, outcomes, and complications.
\end{abstract}

Keywords: Advantages, Complications, Conservative management, Disadvantages, Outcome, Pancreatic pseudocyst, Surgical drainage

\section{INTRODUCTION}

Pancreatic pseudocyst is a localized fluid-containing cyst that follows pancreatitis. It can occur after acute pancreatitis, chronic pancreatitis, and more often after acute exacerbation on top of chronic pancreatitis. They occur in $6 \%$ to $18.5 \%$ of cases after acute pancreatitis, and in $20 \%$ to $40 \%$ of cases after chronic pancreatitis. ${ }^{1,2}$
Pancreatic pseudocysts account for $75-80 \%$ of all cystic lesions that occur in the pancreas. They are well-localized and surrounded by a thick wall that is composed of granulation tissue and collagen.

Pancreatic pseudocyst usually develops few weeks after the onset of pancreatitis. ${ }^{3}$ Diagnosis of pancreatic pseudocyst requires a high index of suspicion because it 
does the clinical presentation is non-specific. Patients with pancreatic pseudocysts present with fever, anorexia, persistent abdominal pain and tenderness after pancreatitis, and abdominal mass. In rare cases, the pseudocyst becomes infected leading to obstructive jaundice. ${ }^{4}$ Computed tomography (CT) abdomen is the investigation of choice for pancreatic pseudocyst diagnosis. ${ }^{5}$

Cyst fluid analysis is beneficial for differentiation between pseudocyst and pancreatic neoplasm. Unlike the neoplasm, cystic fluid analysis in pancreatic pseudocyst reveals low carcinoembryonic antigen 125 (CEA-125), low fluid viscosity, and elevated amylase levels3. Two lines of management are there for treatment of pancreatic pseudocyst: conservative management and surgical drainage. ${ }^{6}$ And this article will compare and review the indications, advantages and disadvantages, outcomes, and complications of both lines.

\section{CONSERVATIVE MANAGEMENT PANCREATIC PSEUDOCYST}

OF

To date, management of pancreatic pseudocyst remains a dilemma. Management comprises two lines: either conservative medical and supportive treatment or surgical drainage of the pseudocyst. None of them seems to be superior to the other in all occasions. The treatment line should be tailored to each particular patient according to his condition. ${ }^{7}$

Conservative medical management includes the use of analgesics, antiemetics, and intravenous fluid for symptomatic relief of the patient conditions. ${ }^{8}$ Other lines include antipyretics, bed rest, dietary adjustment, and intravenous nutrition in certain cases.

Patients with pancreatic pseudocyst should be administered low-fat diet as much as tolerated. In cases who develop incapacitating abdominal pain with eating, intravenous total parenteral nutrition (TPN) or percutaneous jejunal tube should be offered. Activity can be allowed for those patients if they tolerate it. However, bed rest is often recommended. ${ }^{7}$

A list of medications has been evaluated for management of pancreatic pseudocyst. Octreotide comes on the top of this list. It is hypothesized that octreotide would reduce pancreatic secretions and consequently accelerate spontaneous resolution of the pancreatic pseudocyst. ${ }^{9}{ }^{910}$ However, no strong evidence had been provided for its effectiveness in these conditions in the published literature.

A large proportion of pancreatic pseudocysts resolve without operative intervention and only require conservative medical management.

A five-year prospective study and Vitas and Sarr followed 114 patients with pancreatic pseudocyst, 68 of them were managed conservatively, and the rest were surgically operated either electively or on an emergency basis. ${ }^{11}$ More than half of the conservatively-managed patients $(57 \%)$ had their pseudocysts resolved within a six-months follow-up period.

The complication rate was only $9 \%$, and $28 \%$ needed future elective operative procedures for pseudocyst drainage. On the other hand, among the 46 patients who had surgical drainage of their pseudocyst as initial approach, the average morbidity rate was $26 \%(67 \%$ among patients who were indicated for emergency surgical drainage and $10 \%$ among patients who were electively operated). ${ }^{11}$

This ensures the importance of patient selection for deciding the management line to be implemented. Basically, the main aim of treatment of pancreatic pseudocyst is to avoid the occurrence of complications. ${ }^{3,7,12}$ The chief dangerous complications include pseudocyst infection, expansion in size leading to jaundice (symptomatic pseudocysts), and pseudocyst rupture.

Infection occur in about $10 \%$ of the cases. ${ }^{3}$ Rupture, although rare, is a dangerous and almost fatal complication of pancreatic pseudocyst. Rupture into the intestine may result in gastrointestinal bleeding, and rupture into the peritoneum may cause fatal peritonitis. ${ }^{13,14}$ Therefore, the main indications of operative intervention for pseudocyst drainage are pancreatic pseudocyst that are prone to complications, being symptomatic, or debatable diagnosis (e.g. potentially malignant cysts). ${ }^{12,15}$

Most researchers reported that the main indicators of complications and poor prognosis are the size of the cysts and the duration since the onset of cyst development. Larger pseudocysts and cysts that have not resolved for a long period of time without resolution are more likely to cause complications. ${ }^{16}$ Therefore, most physicians prefer surgical drainage of large cysts.

Although surgical drainage is often the of choice line of management in patients with large pancreatic pseudocysts, Vitas and Sarr in their study 11 noted that no serious complications had occurred among patients with large pancreatic pseudocysts $(\geq 10 \mathrm{~cm})$ who were conservatively managed.

Conservative medical management, therefore, provides a safe management option for patients with small asymptomatic pseudocysts that had been developed for a short duration of time. It carries a fair good outcome (more than 50\% spontaneous resolution), low risk for complications (9\%), and low morbidity and mortality. ${ }^{7}$

The main disadvantage, on the other hand, is that it is not suitable for certain patients (symptomatic patients, large- 
sized pseudocysts, complicated cysts, or cysts that had not resolved for a long duration).
The outcome, advantages, disadvantages, and complications of conservative management are summarized in Table 1.

Table 1: Comparison between conservative management and surgical drainage of pancreatic pseudocyst.

\begin{tabular}{|c|c|c|}
\hline & Conservative management & Surgical drainage \\
\hline Outcome & $57 \%$ resolution & $85-90 \%$ success rate \\
\hline Indications & $\begin{array}{l}\text { Small pseudocysts, asymptomatic pseudocysts, } \\
\text { newly-developed cysts }\end{array}$ & $\begin{array}{l}\text { Large pseudocysts, symptomatic } \\
\text { pseudocysts, long-lasting pseudocysts, } \\
\text { development of cysts complications }\end{array}$ \\
\hline Advantages & $\begin{array}{l}\text { Safe, no risk of anaesthesia-associated } \\
\text { complications }\end{array}$ & $\begin{array}{l}\text { Anaesthesia-associated complications, } \\
\text { higher long-term success rates }\end{array}$ \\
\hline Disadvantages & $\begin{array}{l}\text { Lower resolution rate, some patients will need } \\
\text { future operative interventions }\end{array}$ & $\begin{array}{l}\text { Operative risks (infection, haemorrhage, } \\
\text { perforation, operative failure), high cost }\end{array}$ \\
\hline Complication rate & & around $25 \%$ \\
\hline Complications & $\begin{array}{l}\text { Expansion in size (compression on nearby } \\
\text { structures causing gastric outlet obstruction, biliary } \\
\text { complications, portal hypertension, splenic } \\
\text { infarction), rupture of cyst (fatal peritonitis) } \\
\text { haemorrhage }\end{array}$ & $\begin{array}{l}\text { Iatrogenic infection, injury to adjacent } \\
\text { vessels (haemorrhage), operative failure }\end{array}$ \\
\hline Mortality rate & Variable & $3 \%$ \\
\hline
\end{tabular}

\section{SURGICAL DRAINAGE OF PANCREATIC PSEUDOCYST}

Surgical drainage is the second line of management of pancreatic pseudocysts preferred by many physicians. As aforementioned, the main indications for surgery are large-sized pseudocysts (often larger than $5 \mathrm{~cm}$ ), complicated cysts, long-lasting cysts, or suspicion of malignancy. ${ }^{7}$ This group of patients have a high morbidity and mortality, and therefore surgical intervention is necessary. Many researchers, however, argue some of these indications. They claim that the size and duration of pancreatic pseudocysts do not always carry a poor outcome. Some authors reported that large sized pseudocysts (even more than $10 \mathrm{~cm}$ ) did not show serious complications on long-term follow up. ${ }^{17-19}$ Therefore, the main established two indications for surgery are the symptomatic and complicated pseudocysts.

For early detection of any evolving complications, pseudocysts must be closely followed up both clinically and radiologically. Complications of pancreatic pseudocysts include infection, haemorrhage, rupture, biliary complications, gastric outlet obstruction, portal hypertension, and splenic infarction. ${ }^{7}$ Infection occurs in about $10 \%$ of pancreatic pseudocysts. It may occur spontaneously or after diagnostic interventions. ${ }^{12}$ Although some infected pseudocysts may respond to medical therapy, the vast majority of them will require interventional drainage especially when there are signs of sepsis. Haemorrhage is one of the devastating complications of pseudocyst. ${ }^{14}$ It often occurs due to erosion of an adjacent vessel and leads to rapid deterioration up to death. Rupture is another grave complication of pancreatic pseudocyst especially if it occurred in to the peritoneal cavity. ${ }^{13,20}$ Rupture into the gastrointestinal tract is of a better prognosis and it often cause gastrointestinal bleeding either hematemesis or melena). Rupture inside the peritoneum is almost fatal. Symptomatic large pseudocyst at the head of the pancreas can lead to gastric outlet obstruction, whereas large pseudocysts arising at or nearby the tail of pancreas can lead to biliary tract obstruction, obstructive jaundice, and biliary complications. Similarly, compression on splenic and portal veins may lead to portal hypertension, splenic thrombosis, or even infraction. ${ }^{21-23}$

Timing of intervention depends mainly on lesion size, duration, symptoms, and complications. For instance, operative intervention for asymptomatic large pseudocysts can be postponed to six weeks and carried out electively after close monitoring for any early sign of complications. $^{7}$

Symptomatic or complicated cysts should be carried out on a closer basis (within six weeks of diagnosis or even earlier in cases of emergency). If a cyst become symptomatic or if any complication occurred, urgent intervention is indicated whatever the size or duration of the pseudocyst. ${ }^{7,8,12}$

Interventional drainage of pancreatic pseudocysts can be carried out in different approaches. Drainage options include percutaneous external drainage, endoscopic 
drainage, laparoscopic surgical drainage, and open surgical drainage. ${ }^{12}$

To date, none of these approaches was proved to be superior to the others, and the procedure is conducted according to local institutional preferences and available resources. However, the rule is to interfere as minimum as possible and consider conservative approaches maximally. This depends on the patients' conditions.

Percutaneous external drainage comprises percutaneous placement of a drainage pigtail catheter into the pseudocyst fluid cavity under US (ultrasonography) or CT guidance. For best yield and lowest complication rates, 3D US guided drainage is recommended. This ensures the adjacent vessels are not injured. The main drawbacks of this approach are the discomfort caused to the patient and the high risk for infection.

The success rate of this procedure is only around $50 \% .^{24}$ Therefore, it is indicated only in emergency situations for temporary symptomatic relief of the patient until endoscopic or surgical drainage is carried out. Endoscopic drainage is another less invasive interventional method for management of pseudocysts that comprises the use of endoscope for drainage of the cystic fluid either via the biliary duct or through the duodenum. ${ }^{18}$ Despite the high long-term success rates of this approach (80-90\%), it has many limitations. For instance, the pseudocyst may be missed, the drainage catheter may be suboptimally placed, or the adjacent vessels may be injured. Complications occur in 10-20\% of patients, and recurrence may take place in $6-18 \% .^{18}$

Surgical drainage of pancreatic pseudocysts is usually indicated when there is contraindication to or failure of percutaneous external and endoscopic drainage. It can be carried out either laparoscopically or via open surgery. ${ }^{25}$ ${ }^{27}$ Laparoscopic approach is preferred because it is safer, carries low morbidity and mortality risks, and produce almost similar success rates as open surgery. ${ }^{28}$ In both approaches, the drainage is facilitated by creating a stoma between the pseudocyst and the adjacent gastrointestinal tract (stomach, jejunum, or ileum).

Surgical drainage provides a good alternative for patients who do not tolerate endoscopy. Success rates of surgical drainage approaches are reported to range from $85-90 \%$. Complications occur in about $25 \%$, and mortality may evolve in $3 \%$ of patients due to complications. ${ }^{29,30}$

\section{DECISION MANAGEMENT OF PANCREATIC PSEUDOCYST}

Final decision on management of pancreatic pseudocyst in important. It should always be considered that up to $50 \%$ of patients will improve spontaneously without any intervention. Therefore, the decision making should depend upon the patient's profile. ${ }^{24}$ Another consideration to be taken into account during management is that multiple interventional approaches might be necessary for successful drainage of pancreatic pseudocyst. ${ }^{11}$ Patients who have small asymptomatic short-lasting pancreatic pseudocysts should be followed up closely with a wait and watch approach under coverage of conservative medical management6. If any sign of complications occurred, intervention should be considered. Large-sized, symptomatic, long-lasting, or complicated pseudocysts are indicated for interventional drainage. ${ }^{7}$ External percutaneous drainage is only indicated only in cases of emergency for symptomatic relief of patients' complaints until endoscopic or surgical approaches can be conducted. ${ }^{24}$ This is attributed to the low success rates and higher complications and mortality rates.

Endoscopic and surgical drainage approaches have comparable success rates. ${ }^{29}$ However, endoscopic approach is currently more preferable to surgery due to lower complications and mortality associated with it. ${ }^{28,30}$ Surgery is often preserved for patients who do not tolerate endoscopic intervention, those who fail endoscopic treatment and those whose endoscopic management was not optimal. ${ }^{26}$ Still, the choice of approach adopted depends largely on institutional experience, preferences, and the available resources. A comparison between conservative and surgical management of pancreatic pseudocysts is demonstrated in Table 1

\section{CONCLUSION}

Despite the dilemma that still exists regarding the management of pancreatic pseudocysts. The available different lines of management should be tailored to each particular patient according to his own condition. Conservative management is suitable for patients who have small asymptomatic short-lasting pseudocysts, whilst surgical drainage is indicated when the cysts are symptomatic, large in size, long-lasting, or when any complication occurs. Up to $50 \%$ of pancreatic pseudocysts resolve without interventions. Surgical and endoscopic drainage have comparable success rates, but the endoscopic approach has a preferable safety profile.

\section{Funding: No funding sources \\ Conflict of interest: None declared \\ Ethical approval: Not required}

\section{REFERENCES}

1. Imrie CW, Buist LJ, Shearer MG. Importance of cause in the outcome of pancreatic pseudocysts. Am J Surg. 1988;156(3):159-62.

2. Barthet M, Bugallo M, Moreira LS, Bastid C, Sastre B, Sahel J. Management of cysts and pseudocysts complicating chronic pancreatitis. A retrospective study of 143 patients. Gastroenterol Clin Biol. 1993;17(4):270-6. 
3. Habashi S, Draganov P V. Pancreatic pseudocyst. World J Gastroenterol. 2009;15(1):38-47.

4. Delgado RA, Elías JP, Calleja EA, Martínez-Pardo NG, Esteban JI. Pancreatic pseudocyst: less is more. Cir Pediatr. 2009;22(2):55-60.

5. Kim YH, Saini S, Sahani D, Hahn PF, Mueller PR, Auh YH. Imaging diagnosis of cystic pancreatic lesions: pseudocyst versus nonpseudocyst. Radiographics. 2005;25(3):671-85.

6. Levy MJ, Baron TH. Pseudocyst Management. In: Successful Training in Gastrointestinal Endoscopy. Chapter 28. 201;332-340.

7. Khanna AK, Tiwary SK, Kumar P. Pancreatic pseudocyst: Therapeutic dilemma. Int J Inflam. 2012;2012.

8. Jones DR, Vaughan RA, Timberlake GA. Pancreatic pseudocyst: Diagnosis and management. South Med J. 1992;85(7):729-34.

9. Mulligan C, Howell C, Hatley R, Martindale R, Clark J. Conservative management of pediatric pancreatic pseudocyst using octreotide acetate. Am Surg. 1995;61(3):206-09.

10. Nugent CE, Lehman GA, Madura JA, Kopecky K. Pancreatic cancer presenting with resolving pseudocyst during octreotide therapy. Pancreas. 1993;8(4):506-09.

11. Vitas GJ, Sarr MG. Selected management of pancreatic pseudocysts: operative versus expectant management. Surgery. 1992;111(2):123-30.

12. Kaban GK, Perugini RA, Czerniach DR, Litwin DEM. Pancreatic pseudocyst drainage. Oper Tech Gen Surg. 2004;6(1):55-62.

13. Urakami A, Tsunoda $\mathrm{T}$, Kubozoe $\mathrm{T}$, Takeo $\mathrm{T}$, Yamashita K, Imai $\mathrm{H}$. Rupture of a bleeding pancreatic pseudocyst into the stomach. J Hepatobiliary Pancreat Surg. 2002;9(3):383-85.

14. Solheim K, Haarberg G, Skjennald A, Rynning SE, Soreide O, Jensen D. Severe hemorrhage in pancreatic pseudocyst. Alvorlig blodning ved Pancreascyste. 1991;111(13):1616-18.

15. Vitale GC, Lawhon JC, Larson GM, Harrell DJ, Reed DN, MacLeod S. Endoscopic drainage of the pancreatic pseudocyst. Surgery. 1999;126(4):61623.

16. Sharma D, Kataria S, Pathak R, Barua B, Lal R. Laparoscopic drainage of a large pancreatic pseudocyst. J Soc Laproendo Surg. 2012;16(4):67577.

17. Frey CF. Pancreatic pseudocyst-operative strategy. Ann Surg. 1978;188(5):652-62.

18. Roeder BE, Pfau PR. Endoscopic pancreatic pseudocyst drainage. Tech Gastrointest Endosc. 2005;7(4):211-18.
19. Yemos K1, Laopodis B, Yemos J, Scouras K, Rissoti L, Lainas A, et al. Surgical management of pancreatic pseudocyst. Minerva Chir. 1999;54(6):395-402.

20. Afzal M, Ghous SG, Siddiq K. Spontaneous rupture of pancreatic pseudocyst. J Coll Physicians Surg Pakistan. 2004;14(6):370-71.

21. Ungania S, Panocchia N. Splenic artery rupture in pancreatic pseudocyst. Rottura di Arter splenica Pseudocisti Pancreatica. 2000;71(2):251-55.

22. Accetta P, Accetta I, Accetta R, Campos KB, Rodrigues MFO. Pancreatic pseudocyst with splenic involvement. Case report. Rev Col Bras Cir. 2010;37(6):457-59.

23. Botianu PV, Dobre AS, Botianu AM, Onisor D. Pancreatic pseudocyst with splenic artery erosion, retroperitoneal and splenic hematoma. Case Rep Surg. 2015;2015:1-4.

24. Bhasin DK, Rana SS, Sharma V, Rao C, Gupta V, Gupta R, et al. Non-surgical management of pancreatic pseudocysts associated with arterial pseudoaneurysm. Pancreatology. 2013;13(3):25053.

25. Miskic D, Pitlovic V, Latic F, Samardzic J, Miskic B, LaticHodzic L. Laparoscopic transgastric gastrocystostomy pancreatic pseudocyst. Med Arch. 2011;65(6):371-72.

26. Wagh J. Surgical drainage of multiple pancreatic pseudocyst. Pancreatology. 2014;14(2):S2-S3.

27. Zhao X, Feng T, Ji W. Endoscopic versus surgical treatment for pancreatic pseudocyst. Dig Endosc. 2016;28(1):83-91.

28. Varadarajulu S, Bang JY, Sutton BS, Trevino JM, Christein JD, Wilcox CM. Equal efficacy of endoscopic and surgical cystogastrostomy for pancreatic pseudocyst drainage in a randomized trial. Gastroenterol. 2013;145(3):583-90.

29. Aljarabah M, Ammori BJ. Laparoscopic and endoscopic approaches for drainage of pancreatic pseudocysts: A systematic review of published series. Surg Endoscop. 2007:21(11):1936-44.

30. Oida T, Mimatsu K, Kano H, Kawasaki A, Kuboi Y, Fukino N, et al. Laparoscopic cystogastrostomy via the posterior approach for pancreatic pseudocyst drainage. Hepatogastroenterol. 2011;58(110111):1771-5.

Cite this article as: Almaihan A, Matar A, Murshid, E, Al-Ostaz S, Shelby A, Miftah M, et al.

Conservative management versus surgical drainage in pancreatic pseudocyst. Int Surg J 2018;5:2383-7. 